\title{
UNILATERAL PARALYSIS OF THE ELEVATORS OF SUPRANUCLEAR ORIGIN*
}

\author{
BY \\ ENRIQUE MALBRAN AND ATILIO LUIS NORBIS \\ Buenos Aires
}

UNILATERAL paralysis of the elevators (inferior oblique and superior rectus) is a syndrome treated only briefly by most authors (see Duke-Elder, 1949). It is, nevertheless, a relatively frequent clinical entity and of great importance in practice. Bielschowsky (1939) considered this paralysis and the anterior internuclear syndrome to be the only unilateral supranuclear paralysis which could be diagnosed clinically. White (1942) described the syndrome and suggested a useful semiological classification. Malbran (1944, 1949) and Malbran and Sevrin (1952) have accepted Bielschowsky's idea of pathological evolution, and White's classification of the signs.

Apart from clinical reasons, and considering the anatomy only, it is clearly difficult to assign this syndrome to a nuclear or infranuclear lesion. For the first, it would be necessary to accept the existence of a lesion which slowly affected the nuclei corresponding to the superior rectus and inferior oblique, without affecting the intra-ocular muscles and other muscles innervated by the 3rd nerve. An infranuclear lesion is even less probable, as it entails the postulation of a pedicular or truncular lesion which would affect selectively these fibres destined to the two muscles in question. That both elevator muscles of the same eye could be affected by a paralysis of orbital origin is also improbable in view of their anatomical separation.

Per contra clinical arguments favour a supranuclear pathology, as in these cases the integrity of the peripheral neurone can be demonstrated.

In examining a patient with this syndrome, it is possible to ascertain that the movements of elevation of one eye are totally absent; occasionally both muscles appear completely inactive, in other cases the functional deficiency of the inferior oblique is more marked than that of the superior rectus or vice versa. Generally, the patient offers the whole clinical picture of vertical strabismus with descent of the affected eye with pseudo or true ptosis (both forms exist as we will see later).

More rarely the paralysed eye maintains fixation, and the normal eye displays a strong vertical strabismus with elevation in secondary deviation. If the patient is asked to look up, the eye will not usually succeed in rising above the horizontal meridian. There exist, nevertheless, special manoeuvres which enable us to show the integrity of the elevator action of these muscles.

${ }^{*}$ Received for publication May 22, 1954. 
(A) The most precise and objective test is that based upon persistence of a normal Bell's phenomenon. The patient is asked to close his eyes firmly, if the lids of the affected eye are simultaneously separated the upward deviation of the eye may be observed at that moment. This indicates the integrity of the connections between the 3rd and 7th nuclei through the motor connections below these nuclei. The lesion can only exist, therefore, in the corticonuclear connection.

(в) The postural and psycho-optical reflexes are always positive and agree with Bell's phenomenon in demonstrating the undeniable supranuclear origin of this syndrome. In practice, the routine examination only requires a study of the "Duane's following movement". So far as these postural reflexes are studied, it is adequate simply to carry out movement of the head downwards (Schuster's "doll's head phenomenon") whilst the eyes maintain fixation. The absence of the psycho-optical reflex with conservation of these reflexes indicates, according to Bielschowsky (1940) and Fink (1953), a lesion near the nucleus, but with an intact posterior longtitudinal bundle (Case 2).

(c) It is also possible to study the component of rotation, but this is always more difficult than that of elevation. The superior rectus and the inferior oblique are antagonists in their rotary action, the superior rectus being an intorter and the inferior oblique an extorter. If the head is tilted away from the affected eye, the external rotatory muscles of the paralysed eye (the inferior oblique and inferior rectus) are activated at the same time as their vertical antagonists. If the inferior oblique is affected by a paralysis of the nuclear or infranuclear type, the action of the inferior rectus is not checked and the eye is lowered.

This manoeuvre, whilst theoretically acceptable, in practice provides little information. Notwithstanding, in the two cases of our series in which this manoeuvre was possible, a contracture of the inferior rectus was demonstrable by other means. This contracture is of great importance in considering surgical treatment.

TABLE

PARTICULARS OF

\begin{tabular}{|c|c|c|c|c|c|c|c|}
\hline Case Nos. ... & $\ldots$ & $\cdots$ & $\cdots$ & 1 & 2 & 3 & 4 \\
\hline Age at onset (yrs) & $\cdots$ & $\cdots$ & $\cdots$ & 2 & $1 \frac{1}{2}$ & 3 & $\frac{1}{4}$ \\
\hline Paralysed eye & $\cdots$ & $\cdots$ & $\cdots$ & Left & Left & Right & Right \\
\hline \multicolumn{2}{|l|}{ Bell's phenomenon } & $\cdots$ & $\cdots$ & Positive & Positive & Positive & Positive \\
\hline \multicolumn{2}{|l|}{ "Following" reflex } & $\cdots$ & $\cdots$ & Positive & Negative & Positive & Positive \\
\hline \multicolumn{3}{|c|}{ "Cephalic rotation" reflex } & $\ldots$ & Positive & Positive & Positive & Positive \\
\hline \multicolumn{4}{|c|}{\begin{tabular}{ccccc}
$\begin{array}{c}\text { Overaction } \\
\text { oblique }\end{array}$ & \multicolumn{2}{c}{ ipsilateral } & \multicolumn{2}{c}{ superior } \\
& $\cdots$ & $\cdots$ & $\cdots$ & $\cdots$ \\
\end{tabular}} & Negative & Positive & Negative & Negative \\
\hline \multicolumn{4}{|c|}{\begin{tabular}{ccccc}
$\begin{array}{c}\text { Overaction } \\
\text { rectus }\end{array}$ & $\ldots$ & ipsilateral & \multicolumn{2}{c}{ inferior } \\
& $\ldots$ & $\ldots$ & $\ldots$
\end{tabular}} & Negative & Positive & Negative & Negative \\
\hline \multicolumn{2}{|c|}{ Pseudo ptosis or ptosis } & $\cdots$ & $\cdots$ & - & $\begin{array}{l}\text { Pseudo } \\
\text { ptosis }\end{array}$ & $\begin{array}{l}\text { Pseudo } \\
\text { ptosis }\end{array}$ & $\begin{array}{l}\text { Pseudo } \\
\text { ptosis }\end{array}$ \\
\hline Type & $\ldots$ & $\ldots$ & $\ldots$ & 1 & 2 & 2 & 2 \\
\hline
\end{tabular}


White's classification of the three types of monolateral paralysis of both elevators appears to us most useful in deciding on the surgical procedure.

Type 1.-Binocular vision is maintained by tilting the head backwards; this type generally has good vision in both eyes (Case 1).

Type 2.-Fixing with the healthy eye, the paralysed eye is in hypotropia accompanied generally by pseudo ptosis or true ptosis and reduced vision on this side (Cases 2, 3, 4, $6,7,8)$.

Type 3.-Fixing with the paralysed eye which has good vision, the healthy eye with secondary deviation becomes markedly raised and vision is diminished (Case 5).

\section{Case Reports}

The particulars of ten cases described below are set out in the Table.

Case 1, aged 12, attended on June 3, 1953, with a history of onset of strabismus of progressive type at the age of 2 years. 1D sph. lenses had previously been prescribed for both eyes.

\section{Examination}

Head: Tilted backwards to avoid diplopia.

Vision: With glasses, right eye $10 / 10$, left eye $8 / 10$.

Screen Test: 6 m. R.H.* $30^{\Delta}$, exo $9 \Delta$.

Convergence: Both eyes good.

Basic Point of Convergence: $50 \mathrm{~mm}$.

Binocular Vision: Retinal correspondence normal. Fusion at angle of deviation to the following extent-convergence $13^{\Delta}$, divergence $8^{\Delta}$.

Observations.-Bell's phenomenon, and "following" and "cephalic rotation" reflexes positive. Overaction of the homolateral antagonists (left interior rectus and left superior oblique) was absent. Diplopia only occurred on placing the head in the normal position, or on looking upwards.

Type.-As the usual position is a backward head tilt to avoid diplopia and maintain fusion, this case belongs to White's Type 1 .

\section{TEN PATIENTS}

\begin{tabular}{|c|c|c|c|c|c|}
\hline 5 (Fig. 1) & 6 (Fig. 2) & 7 & 8 & 9 (Figs 3 and 4$)$ & 10 (Fig. 5) \\
\hline 39 & At birth & $\frac{1}{2}$ & 12 & At birth & 40 \\
\hline Left & Left & Right & Right & Right & Right \\
\hline Positive & Negative & Positive & Positive & Positive & Negative \\
\hline Positive & Negative & Positive & Positive & Negative & Negative \\
\hline Positive & Negative & Positive & Positive & Negative & Negative \\
\hline Positive & Positive & Positive & Negative & - & Positive \\
\hline - Positive & Negative & Negative & Negative & - & Positive \\
\hline 一 & Ptosis & $\begin{array}{l}\text { Pseudo } \\
\text { ptosis }\end{array}$ & $\begin{array}{l}\text { Pseudo } \\
\text { ptosis }\end{array}$ & $\begin{array}{l}\text { Pseudo } \\
\text { ptosis }\end{array}$ & 一 \\
\hline 3 & 2 & 2 & 2 & 1 & 1 \\
\hline
\end{tabular}

*R.H.= right hyperphoria. 
Surgical Intervention (September 25, 1953).--Right eye, 3-mm. recession of superior rectus. Left eye, marginal myotomy of inferior oblique via conjunctiva.

Follow-up (October 14, 1953).-Screen test, R.H. $9^{\Delta}$, exo $7^{\Delta}$. The patient still retains a slight head tilt.

Case 2, aged 5 years, attended on May 18, 1953, with a history of progressive paralysis since the age of 18 months.

\section{Examination}

Head: Normal position.

Vision: With glasses, both eyes 10/10.

Refraction: Both eyes $+2 \mathrm{D}$ sph.

Fixation: Maintained by right (good) eye.

Screen Test: 6 m. R.H. $18^{\Delta}$, exo $5^{\Delta}$.

Convergence: Both eyes good.

Binocular Vision: Anomalous retinal correspondence.

Observations.-Bell's phenomenon and "cephalic rotation" reflex positive, but "following" reflex negative. On tilting the head and shoulders to the right, the left eye is depressed by a contracture of the left inferior rectus, as shown by the screen test.

Type.-As the patient fixed with the right (good) eye, there was hypotropia of the left eye, accompanied by a pseudo ptosis of the same side, corresponding to White's Type 2 .

Surgical Intervention (October 2, 1953).-Right eye, 3-mm. recession of superior rectus, marginal myotomy of inferior oblique via conjunctiva. Left eye, partial tenotomy of reflected tendon of superior oblique (Berke's operation).

Follow-up (October 29, 1953). - Screen test $6 \mathrm{~m}$. confirms R.H. $8^{\Delta}$, exo $5^{\Delta}$. At a second operation, a recession of left inferior rectus will be necessary if overaction of the type described above is found, and the residual exotropia will have to be corrected.

Case 3, aged 5 years, attended on June 13, 1950. The parents had noticed the deviation at the age of 3 years.

\section{Examination}

Head: Normal position.

Vision: Without glasses: right eye $2 / 10$, left eye, $8 / 10$; with glasses, right eye $4 / 10$, left eye, $8 / 10$.

Refraction: Both eyes $+2 \cdot 0 /+1 \cdot 0 \times 90$.

Fixation: Maintained constantly by left (good) eye.

Screen Test: 6 m. L.H.* $8^{\Delta}$.

Binocular Vision: Normal retinal correspondence.

Observations.-Bell's phenomenon, and "following" and "cephalic rotation" reflexes positive.

Type.-As the patient fixed generally with the good (left) eye, this case belonged to White's Type 2. The pseudo ptosis was not very marked owing to the small degree of vertical deviation.

Surgical Intervention (September 16, 1950).-Left eye, 3-mm. recession of superior rectus.

Follow-up (November 20, 1950).-Patient orthophoric by screen test.

Case 4, aged 37 years, was first seen on May 22, 1950, and gave a history of a slow type of paralysis which began at the age of 3 months.

\section{Examination}

Head: Normal position.

Vision: Right eye, counting fingers, left eye 10/10.

Fixation: Maintained by left eye. 
Screen Test: Not practicable because of lack of fixation in right eye.

Hirschberg Test: L.H. $45^{\Delta}$, eso $35^{\Delta}$.

Binocular Vision: Anomalous retinal correspondence.

Observations.-Bell's phenomenon and "following" and "cephalic rotation" reflexes positive.

Type.-As the patient habitually fixed with the good eye, this case corresponded to White's Type 2. A pseudo ptosis existed also in the right eye.

Surgical Intervention (July 25, 1950).-A marked overaction of the ipsilateral antagonist did not exist, it was practicable to perform a $3-\mathrm{mm}$. myectomy of the superior rectus of the right eye.

Follow-up.-Hirschberg test, L.H. $14^{\Delta}$, eso $35^{\Delta}$.

Second Operation (October 11, 1950).-Right eye 5-mm. recession of medial rectus, $8-\mathrm{mm}$. myectomy of the lateral rectus.

Follow-up (January 13, 1950).- Hirschberg test, L.H. $14^{\triangle}$, eso $14^{\Delta}$. The treatment was not completed, because the patient did not attend again when sent for.

Case 5, aged 41 years, attended on February 14, 1953, with a deviation which had commenced at the age of 39.

Examination (Fig. 1).

Head: Normal position.

Vision: Right eye 2/10. Left eye 8/10.

Fixation: Habitually fixed with left (paralytic) eye.

Screen Test: At $6 \mathrm{~m}$. fixing with left eye, R.H. $60^{\Delta}$, eso $60^{\Delta}$; fixing with right eye, R.H. $40^{\Delta}$, eso $45^{\Delta}$.

Binocular Vision: Normal retinal correspondence, with fusion of a primary degree at angle of deviation.

Convergence: Both eyes good.

Basic Point of Convergence: $70 \mathrm{~mm}$.

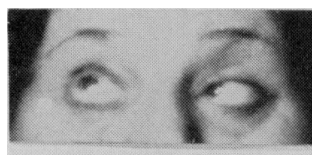

(b)

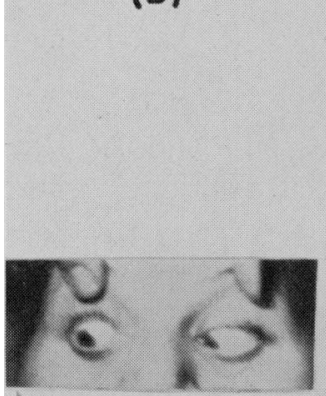

(g)

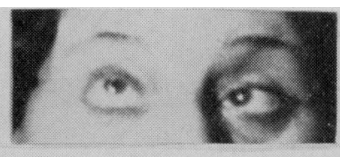

(f)

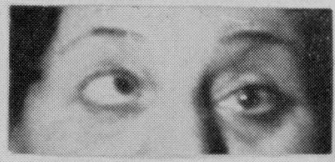

(a)

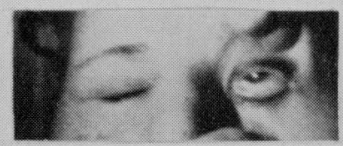

(d)

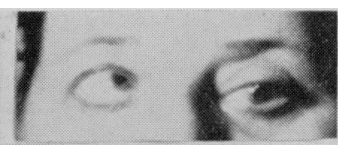

(c)

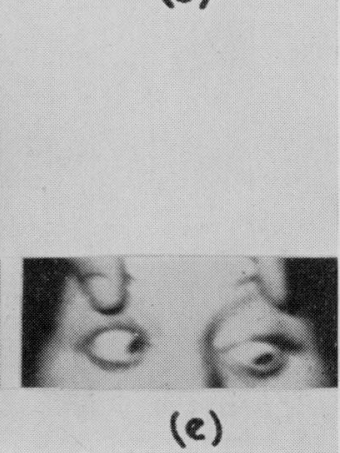

FIG. 1.-Case 5.

(a) In the primary position fixation is carried out with the left (paralytic) eye, and the right eye displays a marked secondary deviation.

(b) Paralysis of left inferior oblique.

(d) Bell's phenomenon present.

(c) Paralysis of left superior rectus.

(e) Overaction of left inferior rectus. 
Observations.-Bell's phenomenon and "following " and " cephalic rotation" reflexes positive. A marked overaction of the superior oblique and inferior rectus was present on the left side (Fig. 1).

Type.-As the patient fixed with the paralytic (left) eye and the good eye displayed a strong secondary deviation, this corresponded to White's Type 3.

Surgical Intervention (January 30, 1954).-Right eye, 3-mm. recession of superior rectus, cinch of lateral rectus (O'Connor's operation). Left eye, partial tenotomy of reflected portion of superior oblique (Berke's operation), $8-\mathrm{mm}$. myectomy of lateral rectus, 5-mm. recession of medial rectus.

Follow-up.-Owing to the short time which has elapsed since the operation, we are not yet able to give the final result.

Case 6, aged 18 years, was first seen on January 1, 1954. This patient was born after a difficult labour, and had shown deviation since birth. The left eye was operated on for ptosis at the age of 9 years (we considered from an erroneous interpretation of the case).

Examination (Fig. 2).

Head: Normal position.

Vision: Right eye $10 / 10$, left eye $1 / 10$.

Fixation: Habitually fixed with right (good) eye.

Screen Test: 6 m. R.H. $45^{\Delta}$, eso $40^{\Delta}$.

Convergence: Both eyes good.

Basic Point of Convergence: $65 \mathrm{~mm}$.

Binocular Vision: Anomalous retinal correspondence.

Observations.-Left eye displays a true ptosis. Bell's phenomenon and "following" and "cephalic rotation" reflexes negative. An overaction of the left superior oblique was present.

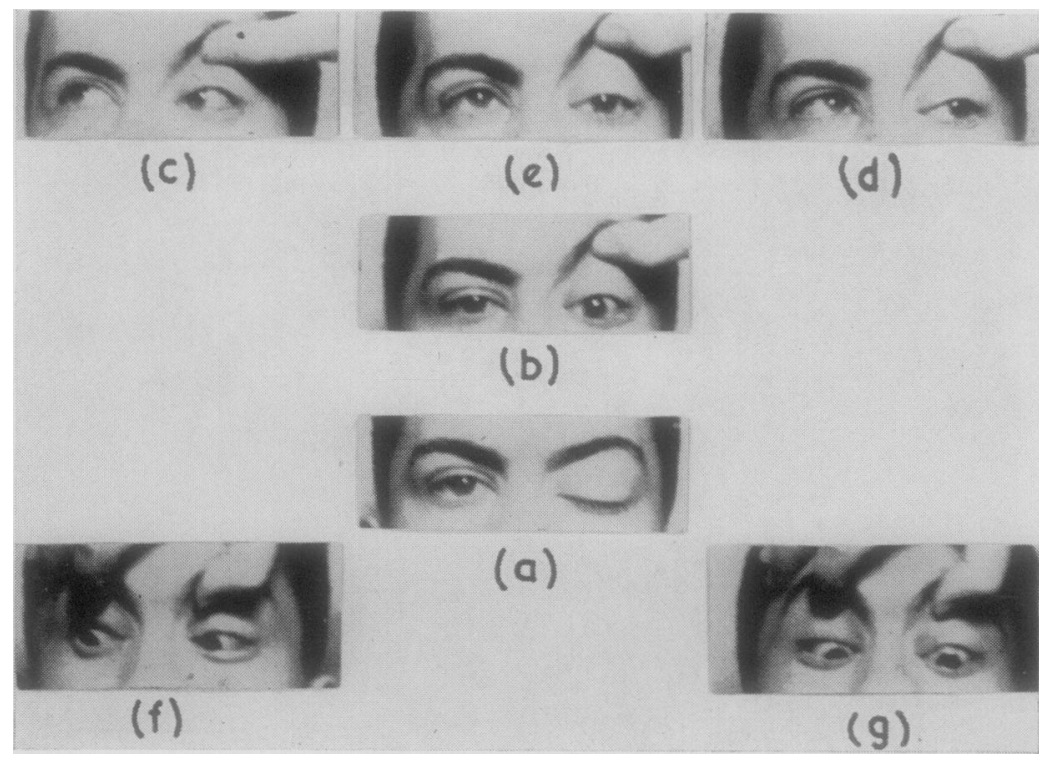

Fig. 2.-Case 6.

(a) Habitual position of patient with marked true ptosis

(b) Passive elevation of left eyelid, showing primary position with fixation by good (right) eye.

(c) and (d) Paralysis of inferior oblique and superior rectus of left side respectively. 
Type.-As the patient fixed habitually with the right (good) eye, this case corresponded to White's Type 2 .

Surgical Intervention (January 23, 1954).-Right eye, 3-mm. recession of superior rectus, 5 - $\mathrm{mm}$. recession of medial rectus, cinch of lateral rectus (O'Connor's operation), marginal myotomy of inferior oblique via conjunctiva. Left eye, $8-\mathrm{mm}$. myectomy of lateral rectus, partial tenotomy of reflected portion of superior oblique (Berke's operation).

Follow-up.- - Owing to the short time which has elapsed since the operation, we are not yet able to give the final result.

Case 7, aged 8 years, first attended on May 5, 1944 with a history of progressive palsy from the age of 6 months.

\section{Examination}

Head: Tilting of head and shoulders to the left.

Vision: With glasses, right eye $1 / 20$, left eye $20 / 20$.

Refraction: Right eye $+3 \mathrm{D}$, left eye $+2 \mathrm{D}$.

Fixation: Fixation had become permanent with left (good) eye.

Screen Test: Fixation impossible with right eye, patient uncooperative.

Hirschberg Test: L.H. $35^{\Delta}$, eso $30^{\Delta}$.

Binocular Vision: Anomalous retinal correspondence.

Observations.-Bell's phenomenon and " following" and " cephalic rotation" reflexes positive. Overaction of right superior oblique.

Type.-As the patient fixed habitually with the left (good) eye, this case corresponded to White's Type 2 .

Surgical Intervention (July 4, 1944).--Right eye, cinch of superior rectus, 5-mm. recession of medial rectus, $8-\mathrm{mm}$. myectomy of external rectus.

Follow-up (August 10, 1944).-Hirschberg test, L.H. $25^{\triangle}$.

Second Operation (November 24, 1945).-Right eye, partial tenotomy of reflected portion of superior oblique (Berke's operation). Left eye, 3-mm. recession of superior rectus.

Follow-up.-Hirschberg test showed orthophoria in primary position. On obstructing fusion with an occluder, $8^{\Delta}$ right hypophoria became evident.

Case 8, aged 25 years, was first seen on July 12, 1949, with a history of paralysis which had begun at age 12 during episodic fever.

\section{Examination}

Head: Normal position.

Vision: Both eyes good, 20/20.

Fixation: Maintained constantly with left (good) eye.

Screen Test: 6 m., L.H. $20^{\Delta}$.

Convergence: Both eyes good.

Basic Point of Convergence: $65 \mathrm{~mm}$.

Binocular Vision: Normal retinal correspondence. Primary degree of fusion at angle of deviation.

Observations.-Bell's phenomenon and "following" and "cephalic rotation" reflexes positive. Pșeudo ptosis of right eye.

Type.-As the patient fixed with the left (good) eye this condition corresponded to White's Type 2.

Surgical Intervention (November 20, 1949).--Right eye, reinforced myectomy of inferior oblique. Left eye, $3-\mathrm{mm}$. recession of superior rectus.

Follow-up.-Screen test confirmed orthophoria in primary position. 


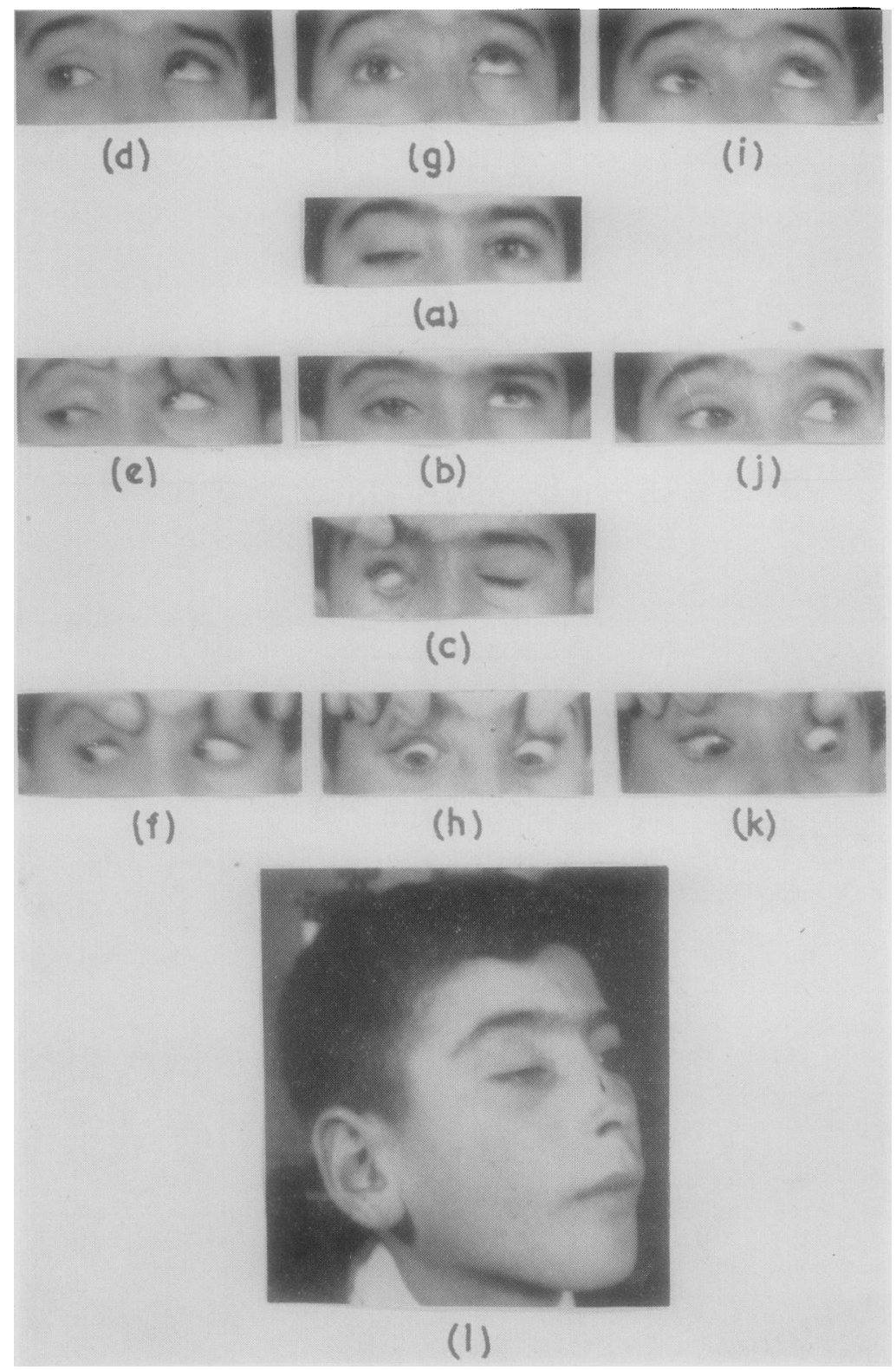

Fig. 3.-Case 9.

(a) Fixing with normal eye, affected eye shows hypotropia and ptosis.

(b) Fixing with paralysed eye, normal eye in secondary deviation upwards.

(c) Bell's phenomenon present in affected eye.

(d) Right superior rectus palsy.

(i) Right inferior oblique palsy.

$(f)$ Fixing with affected eye, showing inhibitional palsy of left superior oblique.

(l) Usual attitude of patient. 
Case 9, aged 12 years, was first seen on June 16, 1954, with a history of deviation present since birth.

Examination (Figs 3 and 4).

Head: Tilted backwards to avoid diplopia. The patient had a ptosis in his usual position that became greatest when his head was tilted forwards.

Vision: Both eyes 10/10.

Screen Test: 6 m., fixing with right eye, L.H. $28^{\Delta}$, exo $10^{\Delta}$; fixing with left eye: L.H. $20^{\Delta}$, exo $7 \triangle$.

Convergence: Both eyes good.

Basic Point of Convergence: $50 \mathrm{~mm}$.

Binocular Vision: Retinal correspondence normal, with after-image and synoptophore tests.

Observations.-The patient could not raise his right eye above the horizontal plane in any field. Bell's phenomenon was present, but the "following" and "cephalic rotation" reflexes could not be obtained. When the patient directed the gaze to the right and down fixing with his right eye, the inhibitional palsy of the left superior oblique was marked. The red-green test showed the right palsy perfectly with the primary and secondary deviation.
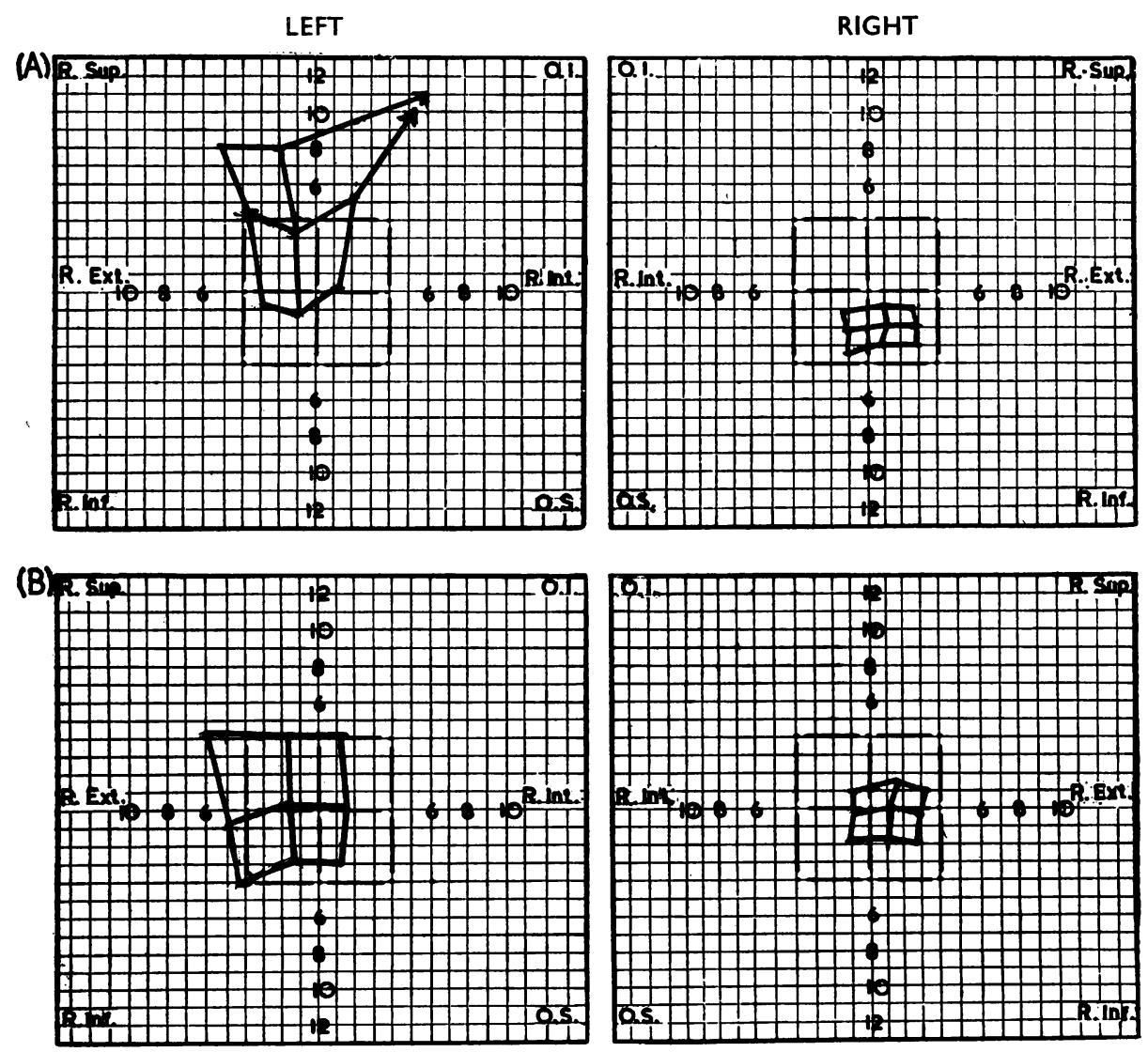

Fig. 4.-Case 9. Unilateral palsy of both elevators in right eye. (A) Before surgery (June 16, 1954). (B) 15 days after surgery (July 2, 1954). Exotropia is seen in the primary position only. 
Type.-As the usual position is a backward head-tilt to avoid diplopia and maintain fusion, this belongs to White's Type 1 .

Surgical Intervention (June 20, 1954).-Right eye, 6-mm. advanced; with 5-mm. resection of inferior oblique (MacLean's operation), 4-mm. resection of superior rectus. Left eye, marginal myotomy of inferior oblique, via conjunctiva.

Follow-up (July 2, 1954). - The patient does not tilt the head backwards, although ptosis is present. Screen test, $6 \mathrm{~m}$., fixing with right eye, exo $12^{\Delta}$; fixing with left eye, : exo $8^{\Delta}$. The vertical deviation occurs only in the upper fields of the gaze.

Case 10 (Fig. 5, opposite), aged 41 years, was first seen on April 12, 1954, with a history of rapid onset one year ago. He had been treated with vitamin $B_{1}$, and leucotropina, but his condition had not improved.

\section{Examination}

Head: Tilted backwards to diminish diplopia.

Vision: Both eyes 10/10.

Screen Test: 6 m., fixing with right eye, L.H. $25^{\Delta}$, exo $18^{\Delta}$; fixing with left eye, L.H. $18^{\triangle}$, exo $18^{\triangle}$.

Convergence: Both eyes good.

Basic Point of Convergence: $50 \mathrm{~mm}$.

Binocular Vision: Retinal correspondence normal, fusional angle of deviation.

Observations.-The patient could not raise the right eye above the horizontal plane. Bell's phenomenon, and "following" and "cephalic rotation" reflexes negative. Fundus normal. Radiographic examinations showed right orbit and optic foramen to be normal. Slight overaction of the ipsilateral antagonist (right inferior rectus and superior oblique) present.

Type.-As the usual position was a backward tilt to avoid diplopia and maintain fusion, this case belonged to White's Type 1 .

Surgical Intervention (May 10, 1954).-Right eye, 4-mm. resection of superior rectus and tucking of inferior oblique. Left eye, marginal myotomy of inferior oblique.

Follow-up (May 20, 1954).- The patient tilts the head to a lesser extent. Screen test, $6 \mathrm{~m}$., fixing with right eye, L.H. $15^{\Delta}$, exo $10^{\Delta}$; fixing with left eye, L.H. $10^{\Delta}$, exo $8^{\Delta}$.

At a later date, it is proposed to perform a 3-mm. recession of the left superior rectus and tenotomy of the reflected right superior oblique (Berke's).

\section{Discussion}

The presence of Bell's phenomenon in seven, the "cephalic rotation" reflex in seven, and the "following" reflex in seven of the ten cases presented, demonstrates clearly the supranuclear origin of this syndrome. Case 6 was unusual in that Bell's phenomenon and the "following" and "cephalic rotation" reflexes were negative, and he presented a true ptosis. In this patient the pathogenic interpretation proved most difficult. Possibly this was an incomplete nuclear paralysis of the 3rd nerve.

In Cases 2, 3, 4, 7, and 8 pseudo ptosis was evident, and in Case 6 true ptosis; in Cases 1 and 5 the palpebral fissure was normal. We wish to stress here the frequency with which this pseudo ptosis may be wrongly regarded as a true partial ptosis, the elevator palsy having been overlooked. In Case 6, for example, a ptosis operation had been performed at another hospital with an unfortunate cosmetic result. 


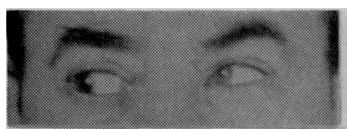

(d)

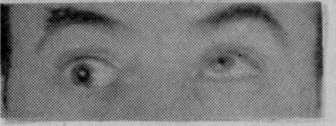

(e)

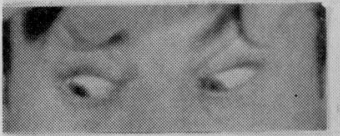

(

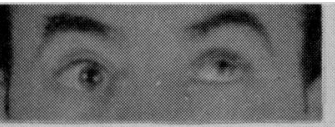

(g)

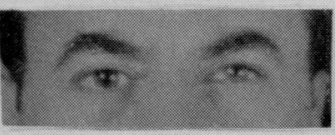

(a)

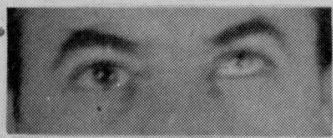

(b)

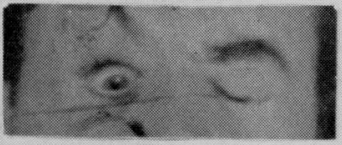

(c)

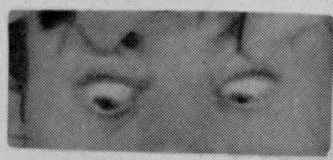

(h)

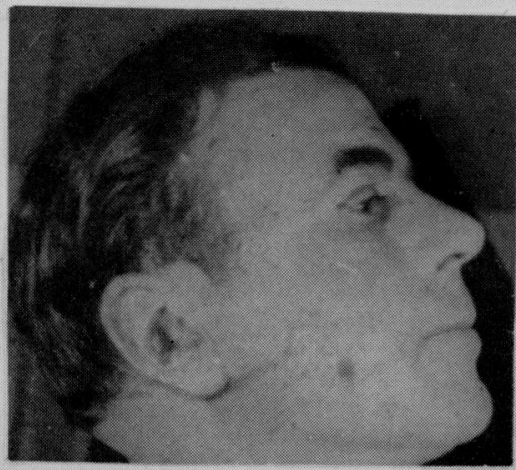

(1)

FIG. 5.-Case 10.

(a) Fixing with good eye.

b) Fixing with affected eye, normal eye in secondary deviation upwards.

(c) Bell's phenomenon absent. (d) Right superior rectus palsy.

(i)

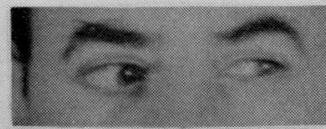

(j)

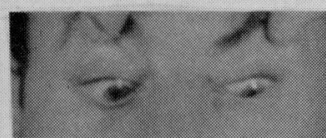

(k)

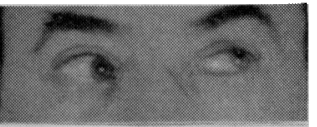

White (1942) only intervened in Type 1 when the head tilt was very marked. $\mathrm{He}$ preferred to strengthen the paralysed muscles, especially the inferior oblique (Wheeler's technique), which he regarded as the muscle most affected, 
and if necessary he strengthened the superior rectus at a second operation. In our only case of this type (Case 1), we operated on the non-paralysed eye (marginal myotomy of inferior oblique via conjunctiva and $3-\mathrm{mm}$. recession of superior rectus). We adopted this technique because the vertical deviation was more marked. The cosmetic result was excellent, although the patient still tilted the head slightly backwards to alleviate the diplopia.

In Type 2, White carried out the same operation as in Type 1. We based our procedure on the existence of muscle overaction in the paretic eye, a very frequent phenomenon. When contracture of the ipsilateral antagonists existed (inferior rectus and superior oblique being the commoner in our experience), we carried out Berke's operation on the superior oblique. If overaction of the inferior rectus was present, we carried out a recession of that muscle; and as this is not always sufficient, we also carried out a weakening operation on the good eye (recession of superior rectus by not more than $3 \mathrm{~mm}$. and marginal myotomy of inferior oblique). Where it was impossible to demonstrate the overaction of the ipsilateral antagonists (Cases 4 and 8) we performed strengthening operations on the paralytic muscles, and weakening operations on the contralateral synergists when the deviation was very marked.

In Type 3, White carried out weakening operations on the superior rectus and inferior oblique of the good eye. In Case 5 we have found it necessaryowing to the large horizontal deviation shown-to correct the vertical component in two operations. Only the first recession of the superior rectus in the good eye, and partial tenotomy of the reflected portion of the superior oblique in the paralytic eye has yet been completed. At the second operation it may be necessary-owing to the great secondary vertical deviation-to complete the correction by a marginal myotomy of the inferior oblique of the good eye, and possibly a recession of the left inferior rectus in the paralytic eye, which was found to be in a state of contracture.

\section{REFERENCES}

Bielschowsky, A. (1939). " Die Lăhmungen der Augenmuskeln ”, In A. Graefe and T. Saemisch, "Handbüch der gesamten Augenheilkunde", 2nd ed., vol. 8, Abt. 1, Kap. 11, Nachtrag 1, p. 43. Springer, Berlin.

(1940). " Lectures on Motor Anomalies"; Dartmouth College Publ., Hanover, N.H.

DUKe-ELDER, S. (1949). " Text-book of Ophthalmology ", vol. 4, p. 4089. Kimpton, London.

FinK, W. H. (1953). Amer. J. Ophthal., 36, 1427.

MALBRAN, J. L. (1944). Arch. Oftal. B. Aires, $19,391$.

(1949). "Estrabismos y Paralisis", cap. 13. Editorial Oftalmologica Argentina, Buenos Aires.

and Sevrin, G. (1952). Bull. Soc. franc. Ophtal., 65, 388.

WHITE, J. W. (1942). Arch. Ophthal. (Chicago), 27, 366. 